\title{
GLOBAL DUST TRANSPORT AS OBSERVED BY A-TRAIN SATELLITES Tao Luo ${ }^{1 *}$, Zhien Wang ${ }^{1}$, Damao Zhang ${ }^{1}$ \\ ${ }^{1}$ University of Wyoming, Dept. Atmospheric Science, Laramie, WY, 82070,USA, *Email: tluo@uwyo.edu
}

\begin{abstract}
This paper presented a new height-resolved view of global dust transport based on 2007-2010 Atrain observations. First, a new dust identification methodology was developed to improve optically thin dust layer detection. Second a new dust partition methodology was developed and applied to CALIPSO lidar measurements to derive dust partitions in external mixed aerosols. These new approaches allow a new view of global dust distribution from dense dust layers near the strong source regions to the optically thin, but significant dust layers from the point of view of aerosolcloud interactions, over the weak source regions, the transport areas, and the upper troposphere. The results will not only help us to better understand global dust transport and dust-cloud interactions, but also provide critical information for model evaluations and improvements.
\end{abstract}

\section{INTRODUCTION}

Dust aerosols are well known for the role in modulating the climate system at local and global scales [1]. The airborne dust mass is of great importance to models in aspects of radiations and cloud microphysics [1,2]. However, current models still have large uncertainties in simulating dust optical depth, vertical extinction profiles and seasonal variations [3], which stresses the need of better dust observations to improve dust related processes in the models, especially in the free troposphere where the dust loading is lower [4, 5]. Reliable height-resolved dust identification and mass estimation approaches are needed to provide more accurate dust loading estimations, and thus to improve our understanding of the mixing of the climate-relevant aerosol components, the long range transport of the dust, and the impact of aerosols on regional climate $[5,6,7]$.

This paper aims to provide a new and complete global height-resolved view of dust distribution by improving thin dust identification based on CloudAerosol Lidar and Infrared Pathfinder Satellite Observations (CALIPSO) Cloud-Aerosol Lidar with Orthogonal Polarization (CALIOP) measurements. Section 2 introduces the data and section 3 introduces the new dust identification and retrieval methodology. Section 4 presents the results and conclusions are in the section 5.

\section{Data}

Nighttime CloudSat and CALIPSO measurements and operational meteorology datasets for the period of January 2007 to December 2010 were used in this study.

CALIOP provides $532-\mathrm{nm}$ total attenuated backscatter $\left(\beta_{532}\right)$ and perpendicular polarization component $\left(\beta_{532 p}\right)$ [8], with 333-m along-track and $30-\mathrm{m}$ vertical resolution below $8.2 \mathrm{~km}$. The CALIOP level 1B data are calibrated and geolocated. The $\beta_{532}$ and $\beta_{532 p}$ data were averaged to a $60-\mathrm{m}$ vertical resolution and were used to identify dust aerosols.

CloudSat carries a 94-GHz cloud profiling radar (CPR), which provides an instantaneous footprint of approximately $1.3 \mathrm{~km}$ (at mean sea level) and has 125 vertical bins with a bin size of about 240 $\mathrm{m}$. The 2B-GEOPROF product provides hydrometeor identification of cloud mask [9].

Temperature and pressure profiles from the European Center for Medium range Weather Forecasting AUX-algorithm (ECMWF-AUX) were used to model molecular backscattering.

\section{METHODOLOGY}

The well-used volume depolarization ratio (VDR) method often misses the thin dust layers [10]. The $\beta_{532 p}$ is more sensitive to the presence of a weak dust layer than the $\beta_{532}$ or VDR, which shows more peaks in weak or dense dust layer signals than in clear sky signals or other types of aerosols or clouds. A new method was developed based on this dust signal characteristic in $\beta_{532 p}$ channel, as following steps. 
Firstly, the cloud information was determined by combining CALIPSO and CloudSat products to better detect optically thin ice clouds with large irregular-shaped particles [11]; Then, for cloudfree regions, peak index was built by identifying and setting the peaks in $\beta_{532 p}$ to be 1 (non-peaks to be 0 ) and were averaged by $6 \times 3$ bins to generate the peak mask. The possible dust layer was identified in the peak index by the threshold of 0.04 , and then refined by a further three-time iterative to set any peaks to zero when the $11 \times 3$ and $21 \times 3$ moving averages of the peak mask are smaller than the clear sky value. The so-derived quick dust mask was further refined by the layerintegrated depolarization ratio (LPDR) to remove other types of aerosols with spherical particles or misidentified clouds. The details can be found in [10].

Then, a new vertically resolved dust separation method based on depolarization measurements was developed to better determine dust loading within a polluted dust layer (dust mixed with other aerosols) by

$\beta_{\text {Total }}^{\prime}(z)=$

$$
\left(\beta_{a}(z)+\beta_{m}(z)\right) e^{-2 \int_{0}^{z}\left(S_{e f f} \beta_{\text {all }}\left(z^{\prime}\right)+S_{m} \beta_{m}\left(z^{\prime}\right)\right) d z^{\prime}}
$$

(1)

$$
\begin{gathered}
\beta_{a}(z)=(1+c) \beta_{d}(z)(2) \\
S_{e f f}=\frac{s_{d}+c S_{n d}}{1+c}(3) \\
c(z)=\frac{\delta_{p}^{\prime}(z)-\delta_{d}^{\prime}(z)}{\delta_{n d}^{\prime}(z)-\delta_{d}^{\prime}(z)}(4)
\end{gathered}
$$

Here, $\beta_{\text {Total }}^{\prime}(z)$ is the measured backscattering coefficient; $\quad \delta_{p}^{\prime}=\frac{\delta_{p}}{\delta_{p}+1} ; \quad \delta_{d}^{\prime}=\frac{\delta_{d}}{\delta_{d}+1} ; \quad \delta_{n d}^{\prime}=$ $\frac{\delta_{n d}}{\delta_{n d}+1} ; \delta_{p}, \delta_{d}$, and $\delta_{n d}$ are depolarization ratios for mixed aerosol, dust and non-dust aerosol respectively; $S_{d}, S_{n d}$ and $S_{m}$ are lidar ratios for dust, non-dust and molecules respectively.

The particle depolarization ratio is less affected by the choice of lidar ratio or retrieval method, which could act as a good constrain to separate dust and non-dust aerosols in polluted dust [12]. Therefore, the first-guess $\delta_{p}$ was retrieved from lidar equation with lidar ratio of 65 . Then, with assumed $S_{d}, S_{n d}, D_{d}$ and $D_{n d}$, height-resolved $S_{e f f}$ can be calculated and $\delta_{p}$ can be retrieve with the updated $S_{\text {eff }}$. Several iterations were performed to retrieve $\delta_{p}$ and update $S_{e f f}$, until the $\delta_{p}$ converges. Finally, the dust backscattering coefficient was separated from the $\beta_{a}$. The sensitive tests showed that the new method retrieves dust backscattering from polluted dusts with uncertainties less than $\sim 11 \%[12]$. More details of this new vertical separation method can be found in [12].

With the retrieved dust extinctions, the polluted dust in dust mask was then further refined to remove any dust mask without dust extinction retrievals. Then, the retrieved dust extinctions were converted to dust mixing ratio with specific extinction coefficient of $0.5 \times 10^{3} \mathrm{~m}^{2} \mathrm{~kg}^{-1}$ at 532 $\mathrm{nm}$ [13].

Lidar signals over South America are strongly affected by the South Atlantic Anomaly (SAA), which results in more noisy spikes in measured signals. This part of the data was removed from the data processing and analysis [11], shown as the blank area over Southern America in Fig. 1.

\section{RESULTS}

Figure 1 shows the $2007-2010$ global $2.5^{\circ} \times 2.5^{\circ}$ mean dust mixing-ratio distributions in December, January, and February (DJF); March, April, and May (MAM); June, July and August (JJA); and September, October, November (SON). The mean mixing ratio was calculated by (total dust mixing ratio)/(total observation number) in each grid box at a given height range. The total observation number includes all sky conditions.

The new dust identification methodology provides a full view of global dust distributions by detecting more dust cases and providing more accurate dust layer boundaries [11], as highlighted in Fig. 1 in terms of dust loading. A main dust band lies from the Sahara dust region to the Asia dust region with strong dust loading at $0-3 \mathrm{~km}$ ranges near the sources and with the dust loading gradually decreasing upward and far away from the source regions.

Over the Sahara and mid-east region (longitude of $20^{\circ} \mathrm{W}$ to $60^{\circ} \mathrm{E}$, latitude of $5^{\circ} \mathrm{N}$ to $33^{\circ} \mathrm{N}$ ), the mean dust loadings with the lower $6 \mathrm{~km}$ AGL are $2.62 \times 10^{-8}, 4.46 \times 10^{-8}, 4.18 \times 10^{-8}$, and $2.79 \times 10^{-8} \mathrm{~kg} / \mathrm{kg}$ for DJF, MAM, JJA and SON 
respectively. The upward transportation of those dust are mainly within lower $6 \mathrm{~km}$ AGL except for MAM (up to $12 \mathrm{~km} \mathrm{AGL)} \mathrm{and} \mathrm{JJA} \mathrm{(up} \mathrm{to} 9$ $\mathrm{km})$. At lower levels $(<6 \mathrm{~km}$ AGL), the western transportation of those dusts is the weakest in DJF. But in other seasons, significant amounts of dust can be transported to the Caribbean Sea and influence North America especially in MAM and JJA. Small amount of those dust can be transported northerly to European, except in MAM, during which dust is transported to cover most of the Northern Hemisphere. African dust can be significantly transported eastward over the Indian Ocean to India at the order of $10^{-8} \mathrm{~kg} / \mathrm{kg}$.

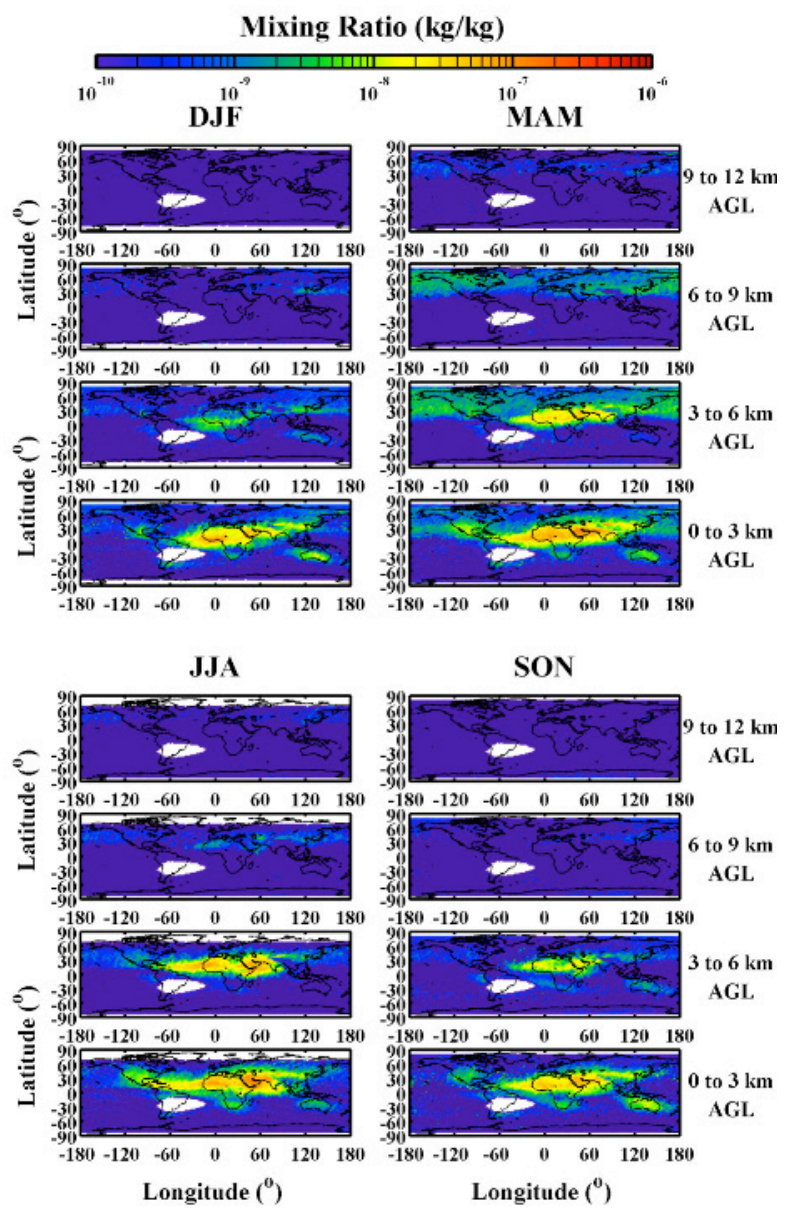

Figure 1. Four-year mean height-resolved global distribution of dust mixing-ratios in different seasons. $3-\mathrm{km}$ vertical bins are used to illustrate dust vertical structure. The blank areas over Arctic and Antarctic indicate the boundaries of satellite observations.
For the Asia dust region, the mean dust mixing ratio in each season over the Taklimakan and Gobi desert those values with the lower $6 \mathrm{~km}$ AGL are $1.29 \times 10^{-8}, 3.6 \times 10^{-8}, 2.23 \times 10^{-8}$, and $1.88 \times 10^{-8} \mathrm{~kg} / \mathrm{kg}$ for DJF, MAM, JJA and SON respectively. The upward transportation of those dusts are main lower than $6 \mathrm{~km}$, and can reach up to $12 \mathrm{~km}$ in MAM, and $9 \mathrm{~km}$ AGL in JJA. The Asia dust can be transported to the east over the Pacific during every season and reaches North America. In MAM, Asian dust can be transported northward over Russia to Arctic.

Over North America, the mean dust loadings are $0.14 \times 10^{-8}, 0.30 \times 10^{-8}, 0.32 \times 10^{-8}$, and $0.24 \times 10^{-8} \mathrm{~kg} / \mathrm{kg}$ for DJF, MAM, JJA and SON respectively. In DFJ and SON, the dust layers are mainly within lower $6 \mathrm{~km}$ with low dust loadings contributed mainly by local sources. The dust loading in MAM and JJA are stronger than DJF and SON, and the dust layer can reach up to 12 $\mathrm{km}$ AGL in MAM and $9 \mathrm{~km}$ AGL in JJA due to long-range dust transportations from Sahara and Asia dust source regions.

Over the Australia dust region, the dusts are mainly from local sources. The dust layers are mainly below $6 \mathrm{~km}$ in DJF and SON, and below 3 $\mathrm{km}$ in MAM and JJA. The dust loadings in the lower $3 \mathrm{~km}$ are $0.25 \times 10^{-8}, 0.25 \times 10^{-8}, 0.20 \times$ $10^{-8}$, and $0.4 \times 10^{-8} \mathrm{~kg} / \mathrm{kg}$ for DJF, MAM, JJA and SON respectively. Those dusts are transported westward to Indian Ocean year round. Furthermore, there are relatively stronger eastward transportations in DFJ and SON than the other seasons.

\section{CONCLUSIONS}

With the newly developed dust identification methodology for improving optically thin dust layer detection, and the newly developed dust partition methodology for externally mixed aerosols, this paper presents a new global heightresolved view of dust transportation based on multi-year A-train satellite observations. The new results allow us to better understand processes controlling dust concentrations over weak source regions, transport areas, and the upper troposphere. One of our ongoing work is to evaluate and improve the model simulations with the dataset. 


\section{ACKNOWLEDGEMENTS}

The CALIPSO dataset was obtained from the NASA Langley Research Center Atmospheric Science Data Center (eosweb.larc.nasa.gov). The CloudSat 2B-GEOPROF and ECMWF-AUX products were obtained from CloudSat Data Processing Center (cloudsat.cira.colostate.edu). This research was funded by NASA grant NNX13AQ41G and a contract from NASA/JPL.

\section{REFERENCES}

[1] IPCC (2007). In: Solomon, S., et al. (Eds.), Climate Change 2007: The Physical Science Basis, Contribution of Working Group I to the Fourth Assessment Report of the Intergovernmental Panel on Climate Change, Cambridge University Press, Cambridge and New York, p. 996.

[2] Zhang, D., Z. Wang, A. Heymsfield, J. Fan, D. Liu, and M. Zhao (2012), Quantifying the Impact of Dust on Heterogeneous Ice Generation in Midlevel Supercooled Stratiform Clouds, Geophys. Res. Lett. (39), L18805.

[3] Evan, A. T., C. Flamant, S. Fiedler, and O. Doherty (2014), An Analysis of Aeolian Dust in Climate Models, Geophys. Res. Lett., 41, 59966001.

[4] Liu, X., X. Shi, K. Zhang, E.J. Jensen, A. Gettelman, D. Barahona, A. Nenes, and P. Lawson (2012b), Sensitivity Studies of Dust Ice Nuclei Effect on Cirrus Clouds with the Community Atmosphere Model CAM5, Atmos. Chem. Phys. (12), 12061-12079.

[5] Uno, I., Z. Wang, M. Chiba, Y. S. Chun, S. L. Gong, Y. Hara, E. Jung, S.-S. Lee, M. Liu, M. Mikami, S. Music, S. Nickovic, S. Satake, Y. Shao, Z. Song, N. Sugimoto, T. Tanaka, and D. L. Westphal (2006), Dust Model Intercomparison (DMIP) Study over Asia: Overview, J. Geophys. Res. (111), D12213.

[6] Johnson, M. S., N., Meskhidze, and V. P., Kiliyanpilakkil (2012), A Global Comparison of GEOS-Chem-predicted and Remotely-sensed Mineral Dust Aerosol Optical Depth and Extinction Profiles. J. Adv. Model. Earth Syst., $4(3)$.

[7] Zhang, D., D. Liu, T. Luo, Z. Wang, and Y.
Yin (2015), Aerosol Impacts on Cloud Thermodynamic Phase Change over East Asia Observed with CALIPSO and CloudSat Measurements, J. Geophys. Res. Atmos., 120.

[8] Winker, D. M., M. A. Vaughan, A. Omar, Y. $\mathrm{Hu}, \mathrm{K}$. A. Powell, Z. Liu, William H. Hunt, and S. A. Young (2009), Overview of the CALIPSO Mission and CALIOP Data Processing Algorithms, J. Atmos. Oceanic Technol. (26), 2310-2323.

[9] Mace, G. (2007), Level 2 GEOPROF Product Process Description and Interface Control Document Algorithm Version 5.3, http://www.cloudsat.cira.colostate.edu/ICD/2BGEOPROF/2B-GEOPROF_PDICD_5.3.doc (last access 08/11/2014).

[10] Luo, T., Z. Wang, D. Zhang, X. Liu, Y. Wang, and R. Yuan (2015), Global Dust Distribution from Improved Thin Dust Layer Detection using A-train Satellite Lidar Observations, Geophys. Res. Lett., 42, 620-628.

[11] Wang, Z., G. Stephens, and T. Deshler (2008), Association of Antarctic Polar Stratospheric Cloud Formation on Tropospheric Cloud Systems, Geophys. Res. Lett. (35), L13806.

[12] Luo, T., Z. Wang, F. A. Richard, C. A. Hostetler, R. Yuan, and D. Zhang, (2015). Vertically Resolved Separation of Dust and other Aerosol Types by a New Depolarization Method. Optics Express 23(11), 14095-14107.

[13] Ansmann, A., P. Seifert, M. Tesche, and U. Wandinger, (2012). Profiling of Fine and Coarse Particle Mass: Case Studies of Saharan dust and Eyjafjallajökull/Grimsvötn Volcanic Plumes. Atmos. Chem. Phys. (12), 9399-9415. 